\title{
Evidence for effective conservation fundraising: Comparing social media with traditional mailshot field experiments
}

\author{
Takahiro Kubo ${ }^{1,2,3, *}$, Hide-Fumi Yokoo ${ }^{4}$, Diogo Veríssimo ${ }^{2}$ \\ ${ }^{1}$ Biodiversity Division, National Institute for Environmental Studies, JAPAN \\ ${ }^{2}$ Department of Zoology, University of Oxford, Oxford, UK \\ ${ }^{3}$ School of Anthropology \& Conservation, University of Kent, UK \\ ${ }^{4}$ Graduate School of Economics, Hitotsubashi University, JAPAN \\ *Correspondence: kubo.takahiro@nies.go.jp
}

\begin{abstract}
Funding shortage limits conservation impact, making it vital to find effective fundraising methods. To explore how traditional and digital conservation fundraising methods perform, we conducted real-world field experiments by using mailshot and Facebook advertisements. We compare three types of message frames (Simple, Seed money, and Ecological) and found that the Seed money frame, which emphasizes the amount already donated, increased the number of donors, whereas the Ecological frame, which focuses on the fact that the fundraiser benefits threatened species, led to a relative reduction in this number. We also found that while on Facebook advertising costs were higher than donations, the opposite was true for the traditional mailshot experiment. Our findings illustrate some of the challenges associated with online fundraising, and importance of behavioral evidence to enhance effective fundraising in conservation.
\end{abstract}

\section{Keywords}

behavioral science; behavior change; biodiversity conservation; donation; Facebook; forest conservation; fundraising; Japan; nudging; social media 


\section{$1 \quad 1$ INTRODUCTION}

2 Funding shortages limit the extent and likely the impact of conservation efforts (Waldron et al.,

3 2017). The latest Global Biodiversity Outlook highlighted the lack of financial resources as a

4 key reason why no Aichi Target was fully achieved (CBD, 2020; Xu et al., 2021). Thus, it is

5 necessary to fill the gap between the available financial resources and those necessary to

6 achieve the biodiversity conservation targets, as highlighted in Target 19 of the first draft of

7 the post-2020 global biodiversity framework (Seidl \& Nunes, 2021; Turnhout et al., 2021).

8 Financial support, including through individual donations has become crucial for biodiversity

9 conservation (Gurney et al., 2021; McCarthy et al., 2012). However, due to the current

10 substantial shortfall, conservation practitioners have been keen to find new and more efficient

11 ways to raise funds.

\subsection{Online fundraising in conservation}

14 Online fundraising is a relatively new approach, capable of reaching a broad target population 15 of donors. Online crowdfunding, for example, raised about 5 million USD for conservation 16 projects across 80 countries from 2009 to 2017 (Gallo-Cajiao et al., 2018). Yet, despite the 17 global reach of online fundraising campaigns for conservation, there has been little empirical evidence around what determines fundraising success. One exception is Kubo et al. (2021) which found that project topics and marketing strategies associated with online findability

20 affected fundraising success. However, this research focused on observational data, which 21 limits the ability to draw causal insights into the drivers of success. Given their budget constraints, conservation practitioners need to consider the effectiveness of different fundraising strategies, from digital using social media platforms such as Facebook to traditional

24 fundraising measures such as traditional direct mail). These insights can go a long way to inform best practice, allowing the conservation practice to move beyond the anecdotal accounts 
and conventional wisdom that still largely dominate fundraising practices (Veríssimo et al., 2018).

\subsection{Behavioral evidence concerning donation behavior}

30 Recently there has been a greater focus on causal inference approaches to obtain rigorous evidence for policy making (Ferraro \& Hanauer, 2014), and an experimental approach is one of the most powerful ways to identify causal impacts (Balmford et al., 2021; Wiik et al., 2020). However, despite the importance of the context in conservation practices, only a few real-world field experiments have been carried out. In terms of offline settings, for example, Salazar et al. (2021) examined the impacts of photographic images on donation behavior at a marine park in Portugal and found no significant difference between four images: dolphins, ocean wildlife, children and watching eyes. Kubo et al. (2018) carried out at a mountain park in Japan and explored the effects of announcing the information on donation behavior for the trail maintenance. They found that seed money was superior to sharing the amount of others' contribution. On the other hand, a single online donation experiment was conducted by using Facebook A/B split tests by Shreedhar (2021) and showed that wild dogs' advertisement videos elicited higher traffic more than elephants' videos, which were counter to prior findings in conservation fundraising (e.g., Thomas-Walters \& J Raihani, 2017). However, up to date, no real-world experimental studies have bridged the gap between online and offline settings in conservation fundraising.

\subsection{Purposes and Message frames}

To fill this knowledge gap, we conducted online and offline real-world field experiments to investigate what types of channels and message frames encourage people to donate more and to what extent different advertising interventions are worth investing in conservation 
51 fundraising. We tested the three types of message frames (Simple, Seed money, and

52 Ecological) as part of a fundraising campaign to purchase private forest for protection with a

53 leading environmental non-governmental association in Japan, the Association of National

54 Trusts in Japan (http://www.ntrust.or.jp/index/top_eng.html). The use of message frames to 55 alter human behavior has received attention in recent literature (e.g., Kusmanoff et al., 2020;

56 Reddy et al., 2020). However, application to the conservation fundraising has been limited and most message framing experiments investigated human attitudes and/or self-reported behavior (Niemiec et al., 2020). Our real-world experiments can go move the field forward by revealing actual donation behavior and giving insight into cost-benefit of the conservation fundraising strategies online and offline and provide solutions to financial shortages in conservation.

\section{METHODS}

\subsection{Study context}

65 Our field experiments were part of a fundraising campaign by the Association of National 66 Trusts in Japan called “Amami rabbit campaign”. This effort was held in 2020/21, and aimied to acquire approximately 5 ha of private forest on Amami Oshima island, Japan. The island is located southwest of the Japanese archipelago, and contains unique sub-tropical rainforests and habitat for endemic and threatened wildlife, including Amami rabbit, Pentalagus furnessi (Sugimura et al., 2000). The rabbit is widely recognized as a locale flagship species, largely through tourism (Kubo et al., 2019). Because of the uniqueness of its ecosystems, a part of

72 Amami island became a natural World Heritage site in 2021 (UNESCO, 2021). The fundraiser attempted to contribute to the conservation of this site because most forests there were private and fragmented, which hampered conservation efforts (IUCN, 2018). The financial target of the campaign was 50000 USD (5 million JPY; hereafter, Japanese yen (JPY) with an exchange 
rate of 100 to the US dollar (USD)). About $55 \%$ (27 500 USD) of it had been raised on July, 2020, when we carried out the research.

\subsection{Experimental design and sampling procedure}

80 In both online and offline experiments, participants were randomly allocated to three groups: 81 Simple (Control), Seed money, and Ecological (Figure 1). Participants in the Simple group received the minimum information about the "Amami rabbit campaign", which described the necessity of funding to acquire and/or manage the forest. The Seed money group received additional information about seed money, which noted $55 \%$ of the fundraising target (i.e., 27 500 USD of 50000 USD) had been collected at that point (July 1st, 2020). Although there is

86 limited evidence in conservation and natural resource management (Kubo et al., 2018), marketing and economics literature suggests publicly announcing seed money increased the number of donors and amount of donations (List \& Lucking-Reiley, 2002). Participants in the Ecological group received information about threatened species. We highlighted that the proportion of threatened mammals on the island (62\%) was higher than the average in Japan

91 (21\%). Highlighting threatened species is a common approach in conservation fundraising (e.g., Clements, 2013); however, few experimental studies evaluated the impacts on donation behavior. For detailed description in the mailshot procedure, see Figure 1 and Table S1. 


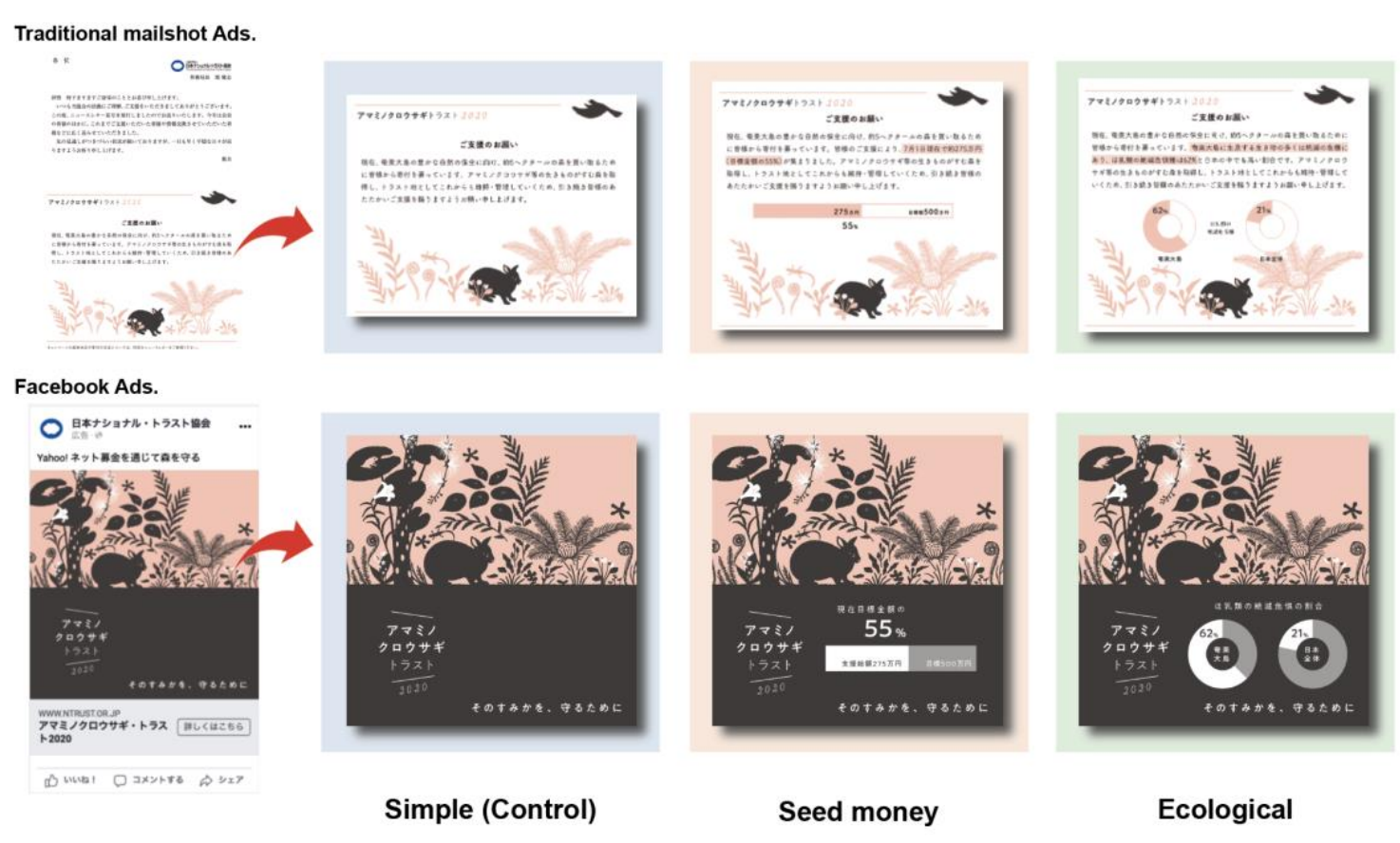

Figure 1. Three types of messaging frames for the traditional mailshot and Facebook campaigns: Simple (Control), Seed money, and Ecological. In addition to the Simple message, the Seed money treatment had additional information about seed money, which noted $55 \%$ of the fundraising target has been collected. The Ecological treatment had additional information about threatened species, which highlighted that the rate of the threatened species on the island (62\%) was higher than the average in Japan (21\%). See Table S1 for the detail.

\subsection{Sampling procedure}

106 In the traditional mailshot appeal, we randomly allocated 630 individuals who had in the past manifested interested in national trust activities (e.g., the national trust members, and previous campaign donors), to one of the experimental groups (i.e., Simple, Seed money, or Ecological). A letter with one of the message frames was sent to them alongside the newsletter of the 110 national trust on July 22nd 2020. The cost associated with shipping and printing was 819 USD.

111 In the online procedure, we applied a similar framework by using Facebook advertisements and a Yahoo! Japan donation webpage. We set the budget to 20 USD per day for each type of 
113 Facebook advertisement and selected the target audience to be Japanese residents and recent

114 visitors to the campaign region, aged 20 years and over, and with a broad interest in nature. We

115 posted the advertisements from October 21st 2020 to December 21st 2020, which cost 3682.44

116 USD in total. When individuals click on the advertisements, they are directed to a Yahoo!

117 Donation webpage. With the support of the national trust and Yahoo! Japan, this study was

118 able to identify those who had seen the advertisement, clicked the link, visited the Yahoo!

119 donation page, and clicked donation buttons for different experimental conditions (i.e., Simple,

120 Seed money, and Ecological). Furthermore, the daily number of actual donors and the daily

121 donation amount were provided by the national trust and Yahoo! Japan.

122

$123 \quad 2.4$ Outcome measures and analysis

124 In the traditional mailshot, two outcome measures were used: donation decision and donation amount. We then applied ordinary least square (OLS) regressions and binary logistic

126 regressions, respectively. In addition to the models using the treatment dummies (i.e., Seed

127 money and Ecological against Simple) as independent variables, we also estimated the models

128 including the membership dummy variable identifying whether those who were the National

129 Trust members or not. The dummy variable and the interaction term with the treatment were

130 added in the model to explore heterogeneous effects of membership.

131 In the online experiment, six outcome variables were used: Impression, Page click, Page view,

132 Donation click, Donation number, and Amount raised. The first two variables were sourced

133 from Facebook and the others from the Yahoo! donation webpage (Figure 2 for details).

134 Impression is defined as the number of times that the adverts are displayed on-screen for

135 audiences on Facebook. The collaboration with the National Trust and Yahoo! Japan let us

136 identify the treatment types on the first four outcome measures (i.e., Impression, Page click,

137 Page view, and Donation click). To investigate the advertisement impacts, we focused on three 
outcome measures: 1) Page view per Impression, 2) Donation click per Impression, and 3)

139 Donation click per Page-view. For each outcome measure, linear regression models with the

140 treatment dummies were applied by considering day fixed effects and robust Heteroskedasticity

141 and Autocorrelation Consistent (HAC) standard errors, to address potential heteroskedasticity

142 and autocorrelation issues. All analyses were conducted by using R version 4.0.5 (R Core Team,

143 2021) and packages lmtest and sandwich (Hothorn et al., 2020; Zeileis et al., 2021). The

144 research was approved by the Ethics Committee of the School of Anthropology and

145 Conservation, University of Kent, UK (No. 011-ST-20); the research had been pre-registered

146 before we carried out the experiment (https://www.socialscienceregistry.org/trials/6152).

147

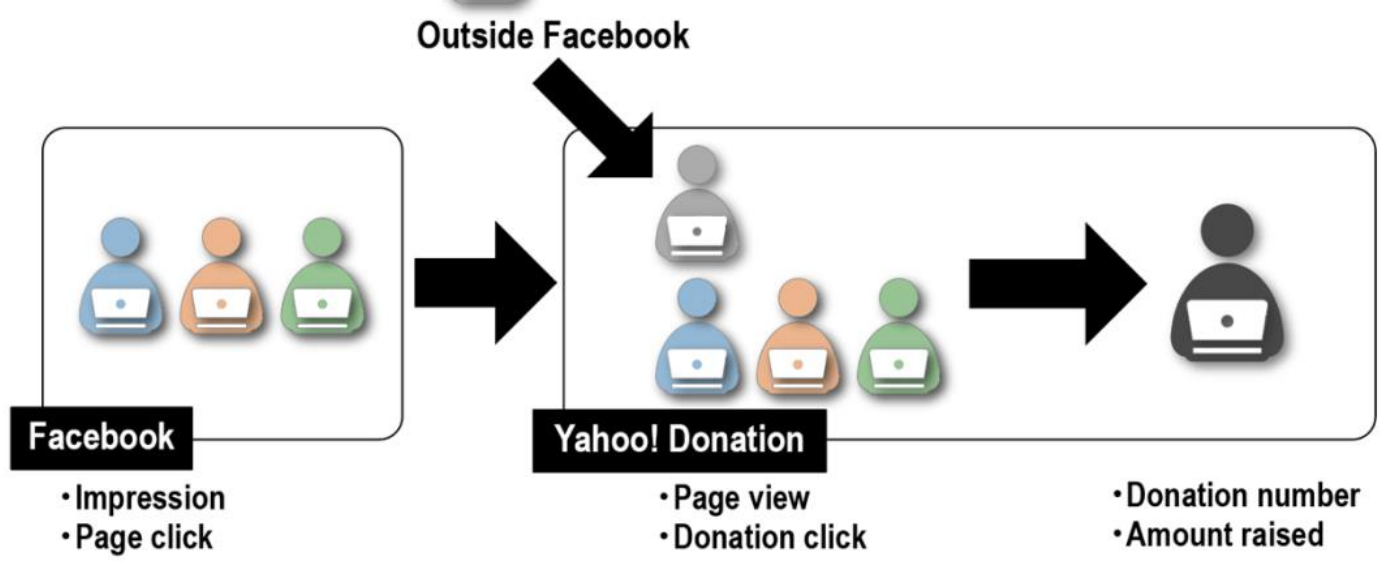

Figure 2. Flowchart of donation behaviour through the online platform (Facebook and Yahoo! Donation website)

\section{RESULTS}

\subsection{Traditional mailshot field experiment}

155 In the traditional fundraising campaign, thirty-eight participants donated, raising a total of 4120

156 USD. Although the donation rate was low (6.03\%), the amount was about five times compared 
to the costs composed of shipping and printing (i.e., USD 819). In the control group, eight

158 participants donated, and the mean and median amount donated were 108 USD and 50 USD,

159 respectively. The donation rate in the Seed money group $(8.57 \%)$ was higher than the control

160 group (3.81\%); whereas the donation rate in the Ecological group (5.71\%) was not statistically

161 different from the control treatment (Table 1 for the details). However, the mean amount raised

162 in both treatment groups (i.e., 117.78 USD in Seed money and 46.67 USD in Ecological) was

163 smaller than that in the control group (i.e., 180.00 USD) although the differences were not

164 statistically significant (Figure 3 and Table S1 for details).

165

166 Table 1. Coefficients for estimated models concerning the mailshot experiment

\begin{tabular}{|c|c|c|c|c|c|c|c|c|}
\hline & \multicolumn{4}{|c|}{ Logit: Donation decision } & \multicolumn{4}{|c|}{ OLS: Amount raised } \\
\hline & \multicolumn{2}{|c|}{ (Treatment) } & \multicolumn{2}{|c|}{$\begin{array}{l}\text { (Treatment } \\
+ \text { Member) }\end{array}$} & \multicolumn{2}{|l|}{ (Treatment) } & \multicolumn{2}{|l|}{$\begin{array}{r}\text { (Treatment } \\
+ \text { Member) }\end{array}$} \\
\hline Constant & $\begin{array}{c}-3.23 \\
{[-4.02,-2.59]}\end{array}$ & $* * *$ & $\begin{array}{c}-3.76 \\
{[-4.94,-2.90]}\end{array}$ & $* * *$ & $\begin{array}{c}6885.71 \\
{[-114.40,1485.83]}\end{array}$ & $*$ & $\begin{array}{c}159.09 \\
{[-708.65,1026.83]}\end{array}$ & \\
\hline Seed money & {$[0.04,1.77]$} & $* *$ & $\begin{array}{c}1.28 \\
{[0.20,2.57]}\end{array}$ & $* *$ & $\begin{array}{c}323.81 \\
{[-807.72,1455.34]}\end{array}$ & & $\begin{array}{c}424.24 \\
{[-841.65,1690.14]}\end{array}$ & \\
\hline Ecological & $\begin{array}{c}0.43 \\
{[-0.48,1.38]}\end{array}$ & & $\begin{array}{c}0.73 \\
{[-0.49,2.09]}\end{array}$ & & $\begin{array}{c}-419.05 \\
{[-1550.58,712.48]}\end{array}$ & & $\begin{array}{c}31.70 \\
{[-1242.99,1306.39]}\end{array}$ & \\
\hline Member & & & $\begin{array}{c}1.75 \\
{[0.26,3.24]}\end{array}$ & $* *$ & & & {$[1096.12,5409.23]$} & $* * *$ \\
\hline $\begin{array}{l}\text { Seed money } \\
\times \text { Member }\end{array}$ & & & -1.34 & & & & -1595.27 & \\
\hline & & & {$[-3.16,0.45]$} & & & & {$[-4415.62,1225.08]$} & \\
\hline $\begin{array}{l}\text { Ecological } \\
\times \text { Member }\end{array}$ & & & -1.08 & & & & -2977.95 & $* *$ \\
\hline & & & {$[-2.99,0.81]$} & & & & {$[-5772.13,-183.76]$} & \\
\hline $\begin{array}{l}\text { Num. Obs. } \\
\quad \text { R2 }\end{array}$ & 630 & & 630 & & $\begin{array}{c}630 \\
0.003\end{array}$ & & $\begin{array}{c}630 \\
0.022\end{array}$ & \\
\hline R2 Adj. & & & & & -0.001 & & 0.014 & \\
\hline $\mathrm{AIC}$ & 288.8 & & 287.9 & & 12734.0 & & 12727.9 & \\
\hline BIC & 302.2 & & 314.6 & & 12751.8 & & 12759.1 & \\
\hline $\begin{array}{l}\text { Log. Lik. } \\
\text { F }\end{array}$ & -141.411 & & -137.964 & & $\begin{array}{c}-6363.001 \\
0.836\end{array}$ & & $\begin{array}{l}-6356.966 \\
2.753\end{array}$ & \\
\hline
\end{tabular}

167

168

169 

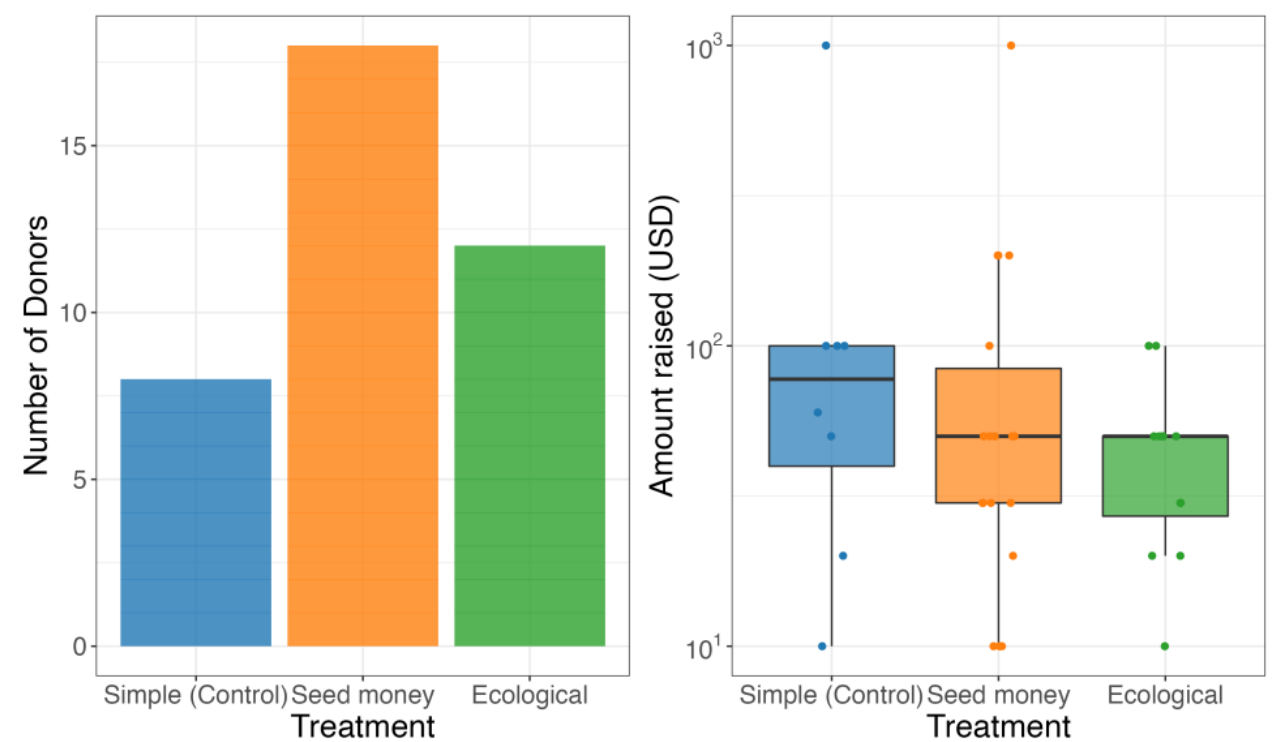

Figure 3. Bar chart (Left) shows the number of donors through the traditional mailshot experiment. Boxplot (Right) shows the amount raised range through that; each dot describes the donation amount by each donor.

\subsection{Online field experiment}

A mean of 20770 people saw the National Trust campaign advertisements each day (i.e., Impression), and 93 people clicked the link and visited the donation page: Yahoo! Japan (i.e., Page clicks). During the Facebook advertisement campaign, the national trust spent 3682.44 USD in Facebook advertisements (a mean of 59.39 USD per day across all three groups) and raised 2908.23 USD in total. This means that costs exceeded the revenue. Note that because the ratio of the donors through the Facebook advertisement was about $22.54 \%$ on average (i.e., about $80 \%$ of donors came from outside Facebook), the monetary return associated with the advertisement would be substantially smaller than the total amount raised.

As Figure 4 described, we also reported the relevant values on Yahoo! platform before, during and after the Facebook interventions. The mean numbers of Page views per day were 35.62 before the campaign, 105.89 during and 11.02 after the campaign. Likewise, the mean numbers of donors were 7.72 (before), 5.02 (during), and 2.85 (after), and the mean amounts raised were 39.96 (before), 46.91 (during), and 12.13 (after), respectively (see Table S3 for more details). 

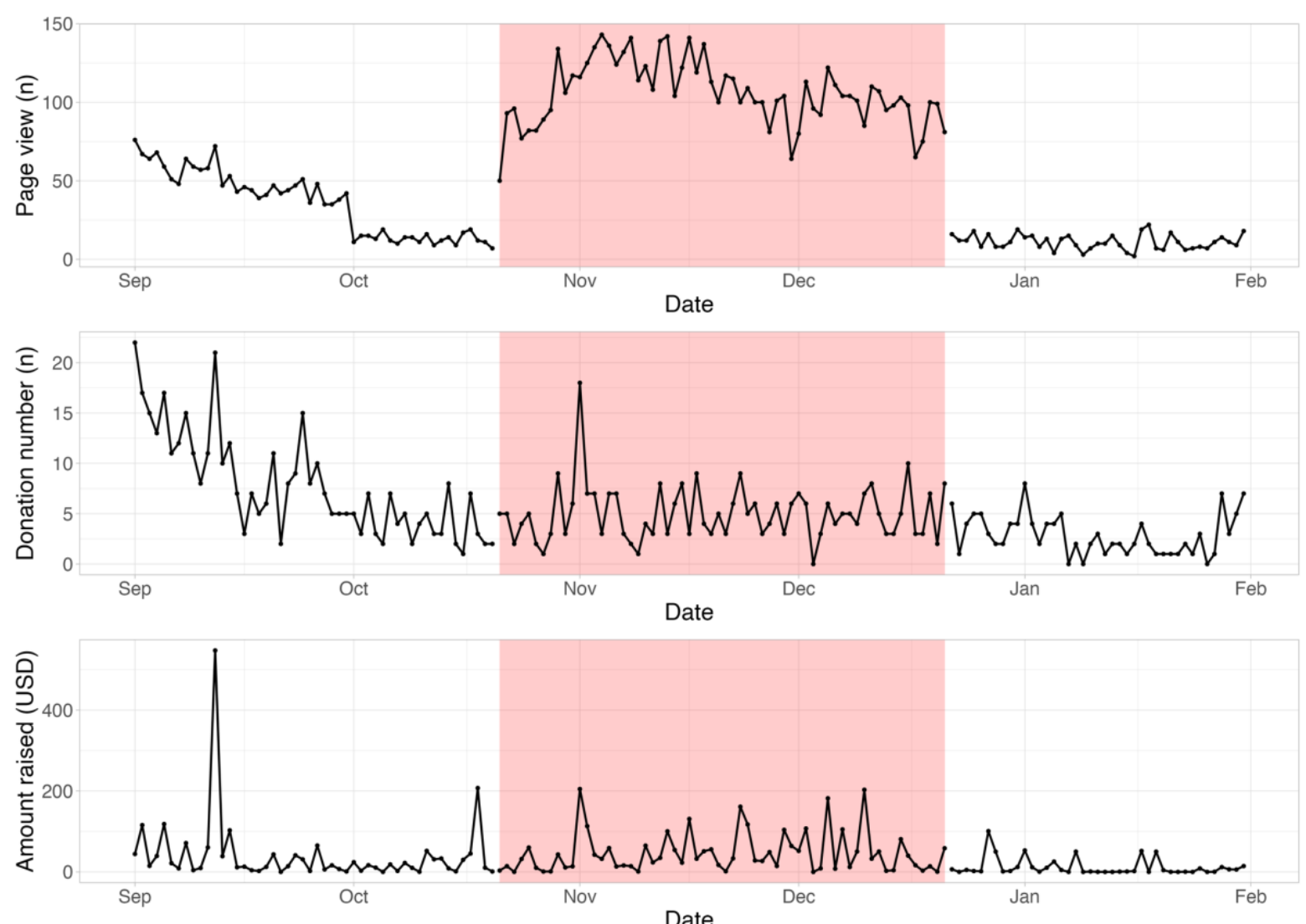

Figure 4. The trends of Page view number (Top), Donor number (Middle), and Amount raised (Bottom). Vertical axes show each value, and horizontal axes show days, respectively. The shaded area is the Facebook advertisement (experiment) period.

On Figure 5, on the one hand, the line graphs describe two control variables (Impression and Page view). The mean numbers of Impressions per day were 5166.65 (Simple), 7469.47 (Seed money), and 8134.27 (Ecological). This differed due to the Facebook algorithm, even if the same daily budget in each treatment group per day was set. The mean numbers of Page views per day were 39.06 (Simple), 28.92 (Seed money), and 25.31 (Ecological). On the other hand, the boxplots on Figure 5 show the three main outcome measures. First, the mean number of Page views per 10000 Impressions were 80.38 (Simple), 40.61 (Seed money) and 32.96 (Ecological), and Simple respectively. Then, the mean number of Donation clicks per 10000 
Impressions were 3.60 (Simple), 2.55 (Seed money), and 1.31 (Ecological). Finally, the mean number of Donation clicks per 100 Page views were 4.37 (Simple), 6.32 (Seed money), and 3.68 (Ecological). Table 2 presents results from the linear regression models of the online experiment data to investigate the effects of each treatment statistically. Simple advertisement increased Page view per Impression and Donation click per Impression compared to the Seed money and Ecological treatments. However, posting the Seed money information raised Donation click per Page view compared to the simple advertisement.

211
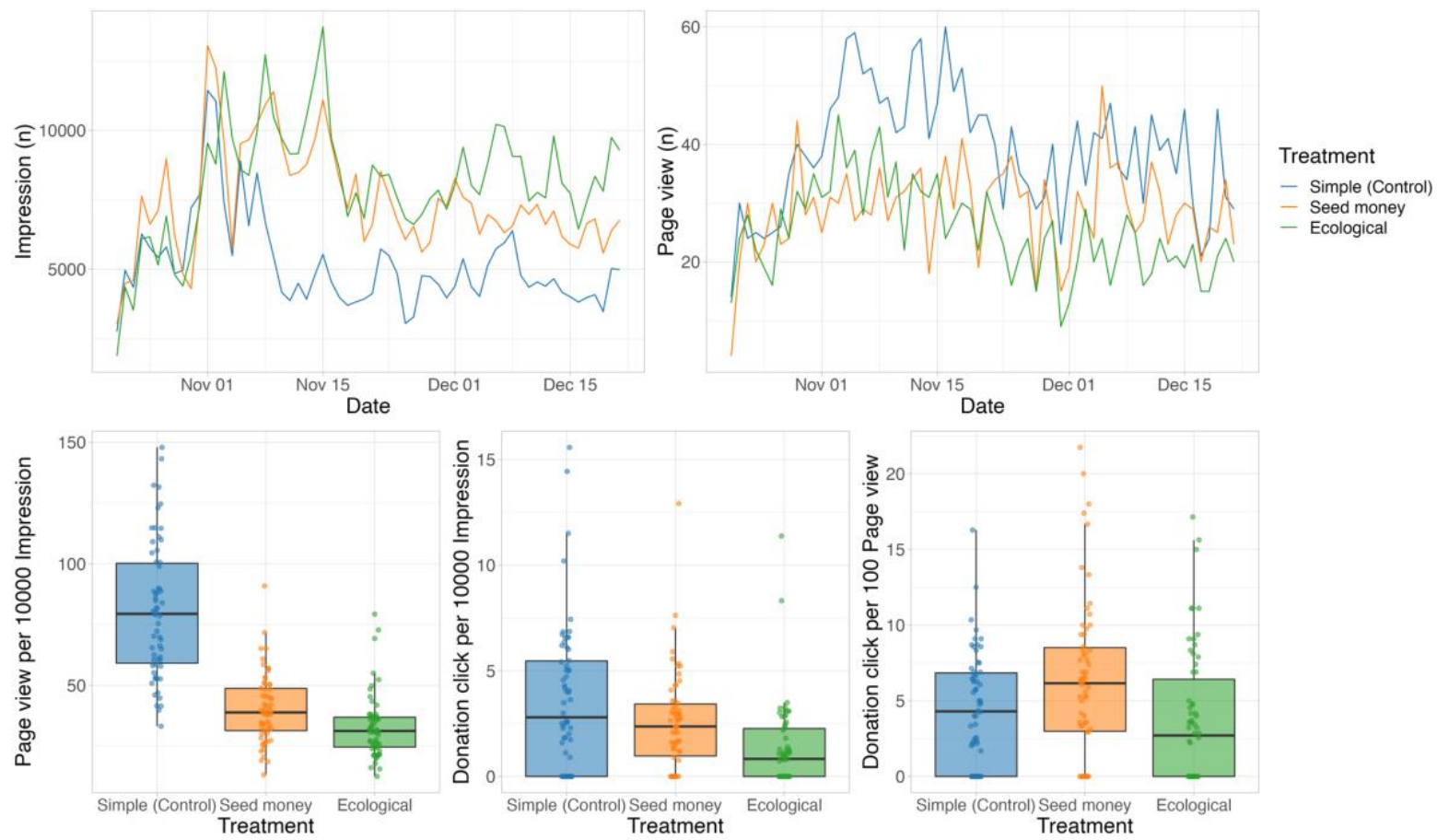

Figure 5. The line figures on the above row show the trend in Impressions and Page view, respectively. Vertical axes show each number and horizontal axes are days. The boxplots on the bottom row describe distributions of three main outcome measures (the number of page views per 10000 Impressions, the number of Donation clicks per 10000 Impressions, and the Donation clicks per 100 Page views) by treatment. 
223 Table 2. Coefficients for estimated models of the online experiment

\begin{tabular}{|c|c|c|c|c|c|c|}
\hline & $\begin{array}{l}\text { Page view } \\
\text { per } 10000 \\
\text { Impression }\end{array}$ & & $\begin{array}{l}\text { Donation click } \\
\text { per } 10000 \\
\text { Impression }\end{array}$ & & $\begin{array}{l}\text { Donation click } \\
\text { per } 100 \\
\text { Page view }\end{array}$ & \\
\hline Intercept & $\begin{array}{c}73.53 \\
{[57.30,89.75]}\end{array}$ & *** & $\begin{array}{c}2.33 \\
{[1.34,3.31]}\end{array}$ & $* * *$ & $\begin{array}{c}1.96 \\
{[-0.540,4.46]}\end{array}$ & \\
\hline Seed money & $\begin{array}{c}-39.77 \\
{[-49.93,-29.61]}\end{array}$ & *** & $\begin{array}{c}-1.05 \\
{[-2.27,0.162]}\end{array}$ & * & $\begin{array}{c}1.96 \\
{[0.326,3.59]}\end{array}$ & ** \\
\hline Ecological & $\begin{array}{c}-47.41 \\
{[-58.75,-36.08]}\end{array}$ & $* * *$ & $\begin{array}{c}-2.29 \\
{[-3.56,-1.03]}\end{array}$ & $* * *$ & $\begin{array}{c}-0.69 \\
{[-2.30,0.915]}\end{array}$ & \\
\hline Day Fixed Effects & YES & & YES & & YES & \\
\hline Num. Obs. & 186 & & 186 & & 186 & \\
\hline R2 & 0.714 & & 0.354 & & 0.397 & \\
\hline R2 Adj. & 0.567 & & 0.021 & & 0.085 & \\
\hline AIC & 1668.1 & & 961.7 & & 1134.5 & \\
\hline $\mathrm{BIC}$ & 1877.7 & & 1171.3 & & 1344.2 & \\
\hline Log.Lik. & -769.034 & & -415.837 & & -502.243 & \\
\hline $\mathrm{F}$ & 4.838 & & 1.063 & & 1.273 & \\
\hline
\end{tabular}

The standard errors and confidence intervals (CIs) were calculated by applying Heteroskedasticity- and autocorrelation-consistent (HAC) estimators of the variancecovariance matrix. The $95 \%$ confidence intervals (CI) are shown in brackets.

$* \mathrm{p}<0.1, * * \mathrm{p}<0.05, * * * \mathrm{p}<0.01$

\section{DISCUSSION}

Rigorous evidence on the most effective and efficient fundraising practices is required to achieve financial targets of the post-2020 biodiversity framework (Turnhout et al., 2021). This is the first real-world experimental study comparing different online and offline fundraising strategies for conservation and assess which are worth investing on. We found that the message framing focused on seed money, outperformed the ecological framing focused on threatened species. We also found that contrary to the mailshot fundraiser, the costs surpassed the income

234 generated through Facebook advertisement although the advertisement raised the number of page views of the donation website. 


\subsection{Traditional mail approach is more cost efficient}

238 Against our expectation, we found that the traditional mail approach was more efficient at 239 raising funds in comparison with social media fundraising. The amount raised by the traditional 240 approach was five times larger than the cost; while the amount against the cost ratio of the 241 online fundraiser was smaller than 1, even though the amount included donations from those who visited the website via non-Facebook advertisements during the advertising period (Table S3). It should however be taken into account the possibility that the use of a pre-existing contact list increased fundraising success of the offline fundraiser by more effectively segmenting the target audience than the segmentation used online. This suggests that when organizations have these lists of contacts online fundraising is likely not worth investing; however, it is not a case of abandoning digital but of understanding when best to use it since digital will remain an important frontier, in particular for organizations looking to expand their donor base beyond those they have already identified as the number of people the organization can reach is far greater online.

\subsection{Insights from pre-donation behaviors}

Before comparing each message frame, we explore online pre-donation behavior: Impressions and Page visits. Our evidence suggests that Impressions and Page visits are not robust measures of success despite its wide use in monitoring and evaluation in conservation and other fields (Doughty et al., 2020), which supports findings represented by recent research (Shreedhar, 2021). Note that our social media advertisement reached hundreds of thousands of people but the conversion rate into donations was very low (Figure. 4). However, even when researchers allocate the same budgets to each group, the algorithm of the online platforms adjusts the reach of advertisement posts to maximize their efficiency, which makes it difficult to test the impacts

261 of interventions. It is therefore key that conservationists carefully unravel the causal 
relationship between investment and outcomes by exploring behavioral evidence to improve their strategy in the future. Collaboration on fundraising between not only conservation

264 practitioners and/or researchers but also online platformers and marketers should be 265 encouraged, which enhance microtargeting in conservation fundraising practices by considering privacy (Metcalf et al., 2019; Thompson et al., 2021).

\subsection{Economic frame overcomes ecological information}

269 Our results reinforce the importance of using marketing insight to guide fundraising efforts and

270 the need for specialist skills within conservation beyond natural science (Kubo et al., 2021;

271 Veríssimo et al., 2017). Findings that publicly announcing seed money encouraged people to

272 donate for fundraising campaigns are consistent with prior literature not only in natural resource management but also in marketing and economics (Gneezy et al., 2014; Kubo et al., 2018). This implies that donation behavior in conservation fundraising might be followed by social information such as conformity (e.g., List \& Lucking-Reiley, 2002). Thus, publicity sharing information on initial budgets from governments and private sectors can improve to fundraising success.

On the other hand, our findings raise questions about the effectiveness of highlighting ecological importance of the campaign target, which is a common approach for many environmental organizations (Clements, 2013; Veríssimo et al., 2017). Highlighting threatened endemic species did not encourage people to donate on both online and offline platforms, and even worse, the information discouraged people from visiting donation websites in comparison with the simple advert. Providing more information can be a barrier to generating interest, and less information can be desirable for the initial interventions. research is needed to monitor the behavior of those who visited the website but not donated at 
the time, and investigate whether they would become future donors. Our evidence emphasizes that knowledge around conservation is often not the best way to get to action and necessity to develop the interventions according to expected actions.

\subsection{Toward effective conservation fundraising}

292 We call on practitioners and organizations to share their experiences, both positive and negative, in fundraising for biodiversity conservation. That will enable practitioners and decision makers to evaluate cost effectiveness of different strategies of conservation fundraising, a practice in line with the thinking in other areas of conservation (Catalano et al., 2019; Game et al., 2014; Kubo et al., 2021; Pienkowski et al., 2021). While there is likely substantial research in this space, most is kept internal with organizations often avoiding discussions around how much they fundraise and how effective they are. Online advertisement campaigns can be a powerful communication tool (Doughty et al., 2020), and the recent COVID-19 pandemic has accelerated online activities over the world (Corlett et al., 2020); however, our evidence reinforces the view that traditional fundraising strategies cannot be simply replaced with online measures without evaluations. Only if we pull together as a field can we deliver the daunting fundraising targets set through the CBD. The integration of behavioral science knowledge into conservation science and practice is crucial to the bold target current being proposed for the post-2020 conservation agenda.

\section{ACKNOWLEDGEMENTS}

309 We would like to thank the Association of National Trusts in Japan and Yahoo! Japan for their

310 cooperation. We also thank Dr. MacMillan and Dr. Yamaguchi for their helpful comments on

311 the research design. TK was funded by the Japan Society for the Promotion of Science. 


\section{REFERENCES}

315 Balmford, A., Bradbury, R. B., Bauer, J. M., Broad, S., Burgess, G., Burgman, M., Byerly, H., Clayton, S., Espelosin, D., Ferraro, P. J., Fisher, B., Garnett, E. E., Jones, J. P. G., Marteau, T. M., Otieno, M., Polasky, S., Ricketts, T. H., Sandbrook, C., Sullivan-Wiley, K., Trevelyan, R., van der Linden, S., Veríssimo, D., \& Nielsen, K. S. (2021). Making more effective use of human behavioural science in conservation interventions. Biological

Conservation, 261, 109256. https://doi.org/https://doi.org/10.1016/j.biocon.2021.109256

322

Catalano, A. S., Lyons-White, J., Mills, M. M., \& Knight, A. T. (2019). Learning from published project failures in conservation. Biological Conservation, 238, 108223. https://doi.org/https://doi.org/10.1016/j.biocon.2019.108223

CBD. (2020). Global Biodiversity Outlook 5. https://www.cbd.int/gbo5

Clements, C. F. (2013). Public interest in the extinction of a species may lead to an increase in donations to a large conservation charity. Biodiversity and Conservation, 22(11), 26952699. https://doi.org/10.1007/s10531-013-0535-z

Corlett, R. T., Primack, R. B., Devictor, V., Maas, B., Goswami, V. R., Bates, A. E., Koh, L. P., Regan, T. J., Loyola, R., Pakeman, R. J., Cumming, G. S., Pidgeon, A., Johns, D., \& Roth, R. (2020). Impacts of the coronavirus pandemic on biodiversity conservation. Biological Conservation, 246 108571. https://doi.org/https://doi.org/10.1016/j.biocon.2020.108571

Doughty, H., Wright, J., Veríssimo, D., Lee, J. S. H., Oliver, K., \& Milner-Gulland, E. J. (2020). Strategic advertising of online news articles as an intervention to influence wildlife 
product consumers. Conservation Science and Practice, 2(10), e272. https://doi.org/https://doi.org/10.1111/csp2.272

338

Ferraro, P. J., \& Hanauer, M. M. (2014). Advances in Measuring the Environmental and Social Impacts of Environmental Programs. Annual Review of Environment and Resources, 39(1), 495-517. https://doi.org/10.1146/annurev-environ-101813-013230

Gallo-Cajiao, E., Archibald, C., Friedman, R., Steven, R., Fuller, R. A., Game, E. T., Morrison, T. H., \& Ritchie, E. G. (2018). Crowdfunding biodiversity conservation. Conservation Biology, 32(6), 1426-1435. https://doi.org/10.1111/cobi.13144

Game, E. T., Meijaard, E., Sheil, D., \& McDonald-Madden, E. (2014). Conservation in a Wicked Complex World; Challenges and Solutions. Conservation Letters, 7(3), 271277. https://doi.org/10.1111/conl.12050

Gneezy, U., Keenan Elizabeth, A., \& Gneezy, A. (2014). Avoiding overhead aversion in charity. Science, 346(6209), 632-635. https://doi.org/10.1126/science.1253932

Gurney, G. G., Darling, E. S., Ahmadia, G. N., Agostini, V. N., Ban, N. C., Blythe, J., Claudet, J., Epstein, G., Estradivari, Himes-Cornell, A., Jonas, H. D., Armitage, D., Campbell, S. J., Cox, C., Friedman, W. R., Gill, D., Lestari, P., Mangubhai, S., McLeod, E., Muthiga, N. A., Naggea, J., Ranaivoson, R., Wenger, A., Yulianto, I., \& Jupiter, S. D. (2021). Biodiversity needs every tool in the box: use OECMs. Nature, 595(7869), 646649. https://doi.org/10.1038/d41586-021-02041-4

Hothorn, T., Zeileis, A., Farebrother, R. W., Cummins, C., Millo, G., \& Mitchell, D. (2020). Package 'lmtest'. http://mirrors.nics.utk.edu/cran/web/packages/lmtest/lmtest.pdf

IUCN. (2018). IUCN World Heritage Evaluations 2018.
http://whc.unesco.org/archive/2018/whc18-42com-inf8B2-en.pdf 
Kubo, T., Mieno, T., \& Kuriyama, K. (2019). Wildlife viewing: The impact of money-back guarantees.

Tourism

Management,

70,

49-55. https://doi.org/10.1016/j.tourman.2018.06.010

Kubo, T., Shoji, Y., Tsuge, T., \& Kuriyama, K. (2018). Voluntary Contributions to Hiking Trail Maintenance: Evidence From a Field Experiment in a National Park, Japan. Ecological Economics, 144, 124-128. https://doi.org/10.1016/j.ecolecon.2017.07.032

Kubo, T., Veríssimo, D., Uryu, S., Mieno, T., \& MacMillan, D. (2021). What determines the success and failure of environmental crowdfunding? Ambio, 50(9), 1659-1669. https://doi.org/10.1007/s13280-021-01522-0

Kusmanoff, A. M., Fidler, F., Gordon, A., Garrard, G. E., \& Bekessy, S. A. (2020). Five lessons to guide more effective biodiversity conservation message framing. Conservation Biology, 34(5), 1131-1141. https://doi.org/10.1111/cobi.13482

List, J. A., \& Lucking-Reiley, D. (2002). The Effects of Seed Money and Refunds on Charitable Giving: Experimental Evidence from a University Capital Campaign. Journal of Political Economy, 110(1), 215-233. https://doi.org/10.1086/324392

McCarthy, D. P., Donald, P. F., Scharlemann, J. P. W., Buchanan, G. M., Balmford, A., Green, J. M. H., Bennun, L. A., Burgess, N. D., Fishpool, L. D. C., Garnett, S. T., Leonard, D. L., Maloney, R. F., Morling, P., Schaefer, H. M., Symes, A., Wiedenfeld, D. A., \& Butchart, S. H. M. (2012). Financial Costs of Meeting Global Biodiversity Conservation Targets: Current Spending and Unmet Needs. Science, 338(6109), 946949. https://doi.org/doi:10.1126/science.1229803

Metcalf, A. L., Phelan, C. N., Pallai, C., Norton, M., Yuhas, B., Finley, J. C., \& Muth, A. (2019). Microtargeting for conservation. Conservation Biology, 33(5), 1141-1150. https://doi.org/10.1111/cobi.13315 
383 Niemiec, R. M., Sekar, S., Gonzalez, M., \& Mertens, A. (2020). The influence of message framing on public beliefs and behaviors related to species reintroduction. Biological https://doi.org/https://doi.org/10.1016/j.biocon.2020.108522

Pienkowski, T., Cook, C., Verma, M., \& Carrasco, L. R. (2021). Conservation costeffectiveness: a review of the evidence base [https://doi.org/10.1111/csp2.357].

and

Practice,

$3(5)$,

e357. https://doi.org/https://doi.org/10.1111/csp2.357

Reddy, S. M. W., Wardropper, C., Weigel, C., Masuda, Y. J., Harden, S., Ranjan, P., Getson,

J. M., Esman, L. A., Ferraro, P., \& Prokopy, L. (2020). Conservation behavior and effects of economic and environmental message frames. Conservation Letters, 13(6),

Salazar, G., Neves, J., Alves, V., Silva, B., \& Veríssimo, D. (2021). Picturing donations: Do images influence conservation fundraising? PLoS One, 16(6), e0251882. https://doi.org/10.1371/journal.pone.0251882

Seidl, A., \& Nunes, P. A. L. D. (2021). Finance for nature: Bridging the blue-green investment gap to inform the post-2020 global biodiversity framework. Ecosystem Services, 51, 101351. https://doi.org/https://doi.org/10.1016/j.ecoser.2021.101351

Shreedhar, G. (2021). Evaluating the impact of storytelling in Facebook advertisements on wildlife conservation

engagement:

Lessons

and challenges [https://doi.org/10.1111/csp2.534]. Conservation Science and Practice, e534. https://doi.org/https://doi.org/10.1111/csp2.534 
Islands, Japan. Oryx, 34(3), 198-206. https://doi.org/10.1046/j.1365$\underline{3008.2000 .00119 . x}$

Thomas-Walters, L., \& J Raihani, N. (2017). Supporting Conservation: The Roles of Flagship Species and Identifiable Victims. Conservation Letters, 10(5), 581-587. https://doi.org/10.1111/conl.12319

412 Thompson, R. M., Hall, J., Morrison, C., Palmer, N. R., \& Roberts, D. L. (2021). Ethics and governance for internet-based conservation science research [https://doi.org/10.1111/cobi.13778]. Biology. https://doi.org/https://doi.org/10.1111/cobi.13778

416 Turnhout, E., McElwee, P., Chiroleu-Assouline, M., Clapp, J., Isenhour, C., Kelemen, E., Jackson, T., Miller, D. C., Rusch, G. M., Spangenberg, J. H., \& Waldron, A. (2021). Enabling transformative economic change in the post-2020 biodiversity agenda [https://doi.org/10.1111/conl.12805]. Conservation Letters, 14(4), e12805. https://doi.org/https://doi.org/10.1111/conl.12805

UNESCO. (2021). Four natural and three cultural sites added to UNESCO's World Heritage List. https://whc.unesco.org/en/news/2318/

Veríssimo, D., Campbell, H. A., Tollington, S., MacMillan, D. C., \& Smith, R. J. (2018). Why 424 do people donate to conservation? Insights from a 'real world' campaign. PLoS One, 13(1), e0191888. https://doi.org/10.1371/journal.pone.0191888 least popular species. Biological Conservation, 211, 95-101. https://doi.org/10.1016/j.biocon.2017.04.018

430 Waldron, A., Miller, D. C., Redding, D., Mooers, A., Kuhn, T. S., Nibbelink, N., Roberts, J. T., Tobias, J. A., \& Gittleman, J. L. (2017). Reductions in global biodiversity loss 
predicted from conservation spending. Nature, 551(7680), 364-367. https://doi.org/10.1038/nature24295

434 Wiik, E., Jones, J. P. G., Pynegar, E., Bottazzi, P., Asquith, N., Gibbons, J., \& Kontoleon, A. (2020). Mechanisms and impacts of an incentive-based conservation program with evidence from a randomized control trial. Conservation Biology, 34(5), 1076-1088. https://doi.org/https://doi.org/10.1111/cobi.13508

438 Xu, H., Cao, Y., Yu, D., Cao, M., He, Y., Gill, M., \& Pereira, H. M. (2021). Ensuring effective implementation of the post-2020 global biodiversity targets. Nature Ecology \& Evolution, 5(4), 411-418. https://doi.org/10.1038/s41559-020-01375-y

441 Zeileis, A., Lumley, T., Graham, N., \& Koell, S. (2021). Package 'sandwich'. https://cran.rproject.org/web/packages/sandwich/sandwich.pdf 


\section{Supporting Information}

Table S1. Information provided on the traditional mailshot advertisement

\begin{tabular}{|c|c|c|}
\hline Simple (Control) & Seed money & Ecological \\
\hline Dear Sir/Madam, & Dear Sir/Madam, & Dear Sir/Madam, \\
\hline $\begin{array}{l}\text { We are pleased to see that you } \\
\text { are doing well. } \\
\text { Thank you for your } \\
\text { understanding and support of the } \\
\text { Association's activities. We are } \\
\text { pleased to send you the summer } \\
\text { issue of our newsletter. This } \\
\text { issue has been sent to our } \\
\text { members and to all those who } \\
\text { have supported us and } \\
\text { exchanged information with us. } \\
\text { We pray for a return to peace } \\
\text { and tranquility as soon as } \\
\text { possible, even though the future } \\
\text { is still difficult to predict. }\end{array}$ & $\begin{array}{l}\text { We are pleased to see that you } \\
\text { are doing well. } \\
\text { Thank you for your } \\
\text { understanding and support of } \\
\text { the Association's activities. We } \\
\text { are pleased to send you the } \\
\text { summer issue of our newsletter. } \\
\text { This issue has been sent to our } \\
\text { members and to all those who } \\
\text { have supported us and } \\
\text { exchanged information with us. } \\
\text { We pray for a return to peace } \\
\text { and tranquility as soon as } \\
\text { possible, even though the future } \\
\text { is still difficult to predict. }\end{array}$ & $\begin{array}{l}\text { We are pleased to see that you } \\
\text { are doing well. } \\
\text { Thank you for your } \\
\text { understanding and support of } \\
\text { the Association's activities. We } \\
\text { are pleased to send you the } \\
\text { summer issue of our newsletter. } \\
\text { This issue has been sent to our } \\
\text { members and to all those who } \\
\text { have supported us and } \\
\text { exchanged information with us. } \\
\text { We pray for a return to peace } \\
\text { and tranquility as soon as } \\
\text { possible, even though the future } \\
\text { is still difficult to predict. }\end{array}$ \\
\hline $\begin{array}{l}\text { Amami Rabbit Trust } 2020- \\
\text { Request for support: } \\
\text { We are currently asking for your } \\
\text { donations to purchase about five } \\
\text { hectares of forest in order to } \\
\text { protect the rich nature of Amami } \\
\text { Oshima Island. } \\
\text { We would like to ask for your } \\
\text { continued support in acquiring } \\
\text { this forest, which is the habitat } \\
\text { for Amami rabbit and other } \\
\text { wildlife, and in maintaining and } \\
\text { managing it as a trust land. }\end{array}$ & $\begin{array}{l}\text { Amami Rabbit Trust } 2020 \text { - } \\
\text { Request for support: } \\
\text { We are currently asking for your } \\
\text { donations to purchase about five } \\
\text { hectares of forest in order to } \\
\text { protect the rich nature of } \\
\text { Amami Oshima Island. } \\
\text { Thanks to your support, as of } \\
\text { 1st July we have raised } \\
\text { approximately } 2.75 \text { million } \\
\text { JPY (55\% of our target). } \\
\text { We would like to ask for your } \\
\text { continued support in acquiring } \\
\text { this forest, which is the habitat } \\
\text { for Amami rabbit and other } \\
\text { wildlife, and in maintaining and } \\
\text { managing it as a trust land. }\end{array}$ & $\begin{array}{l}\text { Amami Rabbit Trust } 2020- \\
\text { Request for support: } \\
\text { We are currently asking for your } \\
\text { donations to purchase about five } \\
\text { hectares of forest in order to } \\
\text { protect the rich nature of Amami } \\
\text { Oshima Island. } \\
\text { Many species of wildlife that } \\
\text { live on Amami Oshima Island } \\
\text { have been threatened with } \\
\text { extinction; among the } \\
\text { mammals, } \mathbf{6 2 \%} \text { has been } \\
\text { endangered, which is one of } \\
\text { the highest rates in Japan. } \\
\text { We would like to ask for your } \\
\text { continued support in acquiring } \\
\text { this forest, which is the habitat } \\
\text { for Amami rabbit and other } \\
\text { wildlife, and in maintaining and } \\
\text { managing it as a trust land. }\end{array}$ \\
\hline
\end{tabular}


Table S2. Descriptive statistics of the traditional mailshot experiment

(Each contribution and raised amount were converted into the US Dollar as $100 \mathrm{JPY}=1 \mathrm{USD}$ ).

\begin{tabular}{lcccc}
\hline & $\begin{array}{c}\text { Total } \\
(\mathrm{n}=630)\end{array}$ & $\begin{array}{c}\text { Simple (Control) } \\
(\mathrm{n}=210)\end{array}$ & $\begin{array}{c}\text { Seed money } \\
(\mathrm{n}=210)\end{array}$ & $\begin{array}{c}\text { Ecological } \\
(\mathrm{n}=210)\end{array}$ \\
\hline Number of Member & 146 & 34 & 54 & 58 \\
Number of Donors & 38 & 8 & 18 & 12 \\
Share of Donors $(\%)$ & 6.03 & 3.81 & 8.57 & 5.71 \\
Mean Amount raised of all samples & 6.54 & 6.86 & 10.10 & 2.67 \\
$\quad[95 \%$ confidence interval] & {$[1.92,11.16]$} & {$[-2.68,16.39]$} & {$[0.11,20.08]$} & {$[0.94,4.39]$} \\
Mean Amount raised of donated samples & 108.42 & 180.00 & 117.78 & 46.67 \\
$\quad[95 \%$ confidence interval] & {$[36.49,180.35]$} & {$[-98.61,458.61]$} & {$[3.54,232.01]$} & {$[28.43,64.91]$} \\
Total Amount raised & 4120 & 1440 & 2120 & 560 \\
\hline
\end{tabular}


Table S3. Descriptive statistics of the online platforms (i.e., Facebook and Yahoo! Donation)

\begin{tabular}{|c|c|c|c|c|c|c|}
\hline & \multirow[t]{2}{*}{ Before } & \multirow[t]{2}{*}{ During } & \multicolumn{3}{|c|}{ (Breakdown of each group) } & \multirow[t]{2}{*}{ After } \\
\hline & & & (Simple & Seed money & Ecological) & \\
\hline \multicolumn{7}{|l|}{ Facebook } \\
\hline Mean advertisement cost per day & - & 59.39 & 19.80 & 19.80 & 19.80 & - \\
\hline [95\% confidence interval] & - & {$[58.27,60.52]$} & {$[19.42,20.17]$} & {$[19.42,20.18]$} & {$[19.42,20.18]$} & - \\
\hline Mean Impression per day & - & 20770.39 & 5166.65 & 7469.47 & 8134.27 & - \\
\hline [95\% confidence interval] & - & [19573.86, 21966.91] & {$[4744.64,5588.65]$} & {$[6977.61,7961.33]$} & {$[7600.19,8668.36]$} & - \\
\hline Mean Page click per day & - & 93.30 & 41.65 & 35.31 & 34.44 & - \\
\hline [95\% confidence interval] & - & {$[88.04,98.54]$} & {$[39.06,44.23]$} & {$[33.19,37.42]$} & {$[31.86,37.01]$} & - \\
\hline \multicolumn{7}{|l|}{ Yahoo! Donation } \\
\hline Mean Page view per day ${ }^{* 1}$ & 35.62 & 105.89 & 39.06 & 28.92 & 25.31 & 11.02 \\
\hline$[95 \% \text { confidence interval }]_{* 2 * 3}$ & {$[29.74,41.50]$} & {$[100.64,111.14]$} & {$[36.44,41.69]$} & {$[27.03,30.80]$} & {$[23.36,27.25]$} & {$[9.51,12.54]$} \\
\hline Mean Donation click per day ${ }^{* 2, * 3}$ & 26.61 & 20.92 & 1.73 & 1.82 & 1.00 & 9.12 \\
\hline $\begin{array}{c}{[95 \% \text { confidence interval }]} \\
\text { Mean Donor number per dav }\end{array}$ & {$\left[\begin{array}{c}23.99,29.23] \\
7.72\end{array}\right.$} & $\begin{array}{c}{[19.41,22.43]} \\
5.02\end{array}$ & {$[1.32,2.13]$} & {$[1.41,2.23]$} & {$[0.67,1.32]$} & $\begin{array}{c}{[7.02,11.22]} \\
2.85\end{array}$ \\
\hline [95\% confidence interval] & {$[6.26,9.18]$} & {$[4.31,5.73]$} & - & - & - & {$[2.22,3.49]$} \\
\hline Mean Amount raised per day & 39.96 & 46.91 & - & - & - & 12.13 \\
\hline [95\% confidence interval] & {$[16.45,63.47]$} & {$[34.13,59.69]$} & - & - & - & {$[5.28,18.98]$} \\
\hline Total Amount raised & 1998.21 & 2908.23 & - & - & - & 497.37 \\
\hline
\end{tabular}

${ }^{* 1}$ The number of Page view in the column "During" the experiment is composed of both viewers through the Facebook and other sources; however, the number of breakdown was composed of the donors only through the Facebook.

${ }^{* 2}$ The number of Donation clicks had been recorded since September 23 although the others on the Yahoo! Japan platform had been done since September $1^{\text {st }}$

because of the technical limitations of the platform at the time.

*3 The number of Donation clicks in the column "During" the experiment is composed of both donors through the Facebook and outside the Facebook (see Figure S1); however, the number of breakdown was composed of the donors only through the Facebook. 